\title{
High-grade primary pulmonary leiomyosarcoma
}

\author{
Leiomiossarcoma primário de alto grau do pulmão \\ Rodrigo Afonso da Silva Sardenberg ${ }^{1}$, Renato Cangnaci Neto ${ }^{1}$, Fernanda Cavalcanti ${ }^{2}$, Riad Naim Younes ${ }^{3}$
}

\section{ABSTRACT}

Primary sarcomas of the lung are rare and account for $0.5 \%$ of all primary lung tumors. There were approximately 300 cases described in the literature as of 2006. All histologic types of sarcoma were described, and the most common intrathoracic types reported were angiosarcoma, leiomyosarcoma, fibrosarcoma, hemangiopericytoma, and rhabdomyosarcoma. The biological behavior of these tumors is not well-known due to their low frequency. Leiomyosarcomas represent one of the most common subtypes encountered in the lungs, and usually occur during the sixth decade, with male predominance. Although the frequency of metastatic disease is not related to tumor size, prognosis was reported to be poorer in high-grade tumors. In comparison with other sarcomas, survival after complete resection of pulmonary leiomyosarcoma was reported as longer. We report on a patient with primary leiomyosarcoma originating from the bronchus with complete resection and long-term follow-up.

Keywords: Leiomyosarcoma; Lung neoplasms; Sarcoma; Case reports

\section{RESUMO}

Os sarcomas primários do pulmão são raros e representam aproximadamente $0,5 \%$ de todas as neoplasias pulmonares. Havia aproximadamente 300 casos descritos na literatura até 2006. Todos os tipos histológicos foram relatados, sendo que os sarcomas intratorácicos mais comuns são o angiossarcoma, leiomiossarcoma, fibrossarcoma, hemangiopericitoma e rabdomiossarcoma. Devido à sua baixa frequência, o comportamento biológico desses tumores não é bem conhecido. 0 leiomiossarcoma é um dos subtipos mais encontrados no pulmão, e normalmente ocorre na sexta década de vida com predominância nos homens. Embora a frequência de doença metastática não esteja relacionada ao tamanho do tumor, 0 prognóstico é pior nos tumores de alto grau. Quando comparados a outros sarcomas, a sobrevida após a ressecção completa dos leiomiossarcomas de pulmão é mais prolongada. Relatamos o caso de um paciente com leiomiossarcoma primário de pulmão de origem brônquica tratado com ressecção completa e seguimento de longo prazo.

Descritores: Leiomiossarcoma; Neoplasias pulmonares; Sarcoma; Relatos de casos

\section{INTRODUCTION}

Primary lung sarcomas are considered extremely rare tumors. They account for $0.5 \%$ of all primary malignancy lung disease ${ }^{(1)}$. All histologic types of sarcoma were described in the literature and the most common intrathoracic types reported were angiosarcoma, leiomyosarcoma, fibrosarcoma, hemangiopericytoma, and rhabdomyosarcoma ${ }^{(1,2)}$. Due to the limited number of cases, there are only few series describing the management of these tumors ${ }^{(3)}$. Diagnosis can be made only after clinical, pathologic and imaging investigation $^{(1)}$. Very often, clinical investigation is non-diagnostic, with final histology characterization achieved only after surgical resection. Since the advent of immunohistochemistry, great progress has been made in the proper identification and classification of these neoplasms, further aiding in their management. Likewise in other sarcomas, surgery remains the mainstay of treatment.

In 1952, Johnson et al. documented the first case of primary leiomyosarcoma of the lung (PLL) successfully treated by pneumonectomy ${ }^{(4)}$. There has been a gradual increase in the number of reported cases regarding this tumor since then.

A case is presented of a patient with PLL originating from the bronchus with clinical, imaging, and pathologic findings, and long-term follow-up as well.

\section{CASE REPORT}

A 44-year-old man, with no previous symptoms, presented with a mass in the right lung on a routine chest $\mathrm{X}$-ray. He was in good health condition and had a history of smoking for the past 20 years (30 cigarettes/day). The clinical examination showed no remarkable findings and laboratory tests were normal. Computed tomography (CT) of the chest showed a $50-\mathrm{mm}$ lobulated mass

\footnotetext{
'Hospital AC Camargo - São Paulo (SP), Brazil.

${ }^{2}$ Hospital Oswaldo Cruz - São Paulo (SP), Brazil.

${ }^{3}$ Instituto do Câncer do Estado de São Paulo - ICESP, São Paulo (SP), Brazil; Faculdade de Medicina, Universidade de São Paulo - USP, São Paulo (SP), Brazil.

Corresponding author: Rodrigo Afonso da Silva Sardenberg - Avenida Albert Einstein, 627 - 4 andar, consultório 419B - Morumbi - CEP 05651-901 - São Paulo (SP), Brazil - Tel.: (11) 2151-9419 -

E-mail: rodafs@uol.com.br

Received on: Sep 13, 2010 - Accepted on: Oct 28, 2011
} 
in the right lower lobe (RLL) with no mediastinal adenopathy (Figure 1). The 18F-FDG positron emission tomography revealed a 1.92 SUV mass in the RLL with no distant disease (Figure 2). Magnetic resonance of the brain was normal. Bronchoscopy was normal and the transbronchial biopsy revealed no tumor.

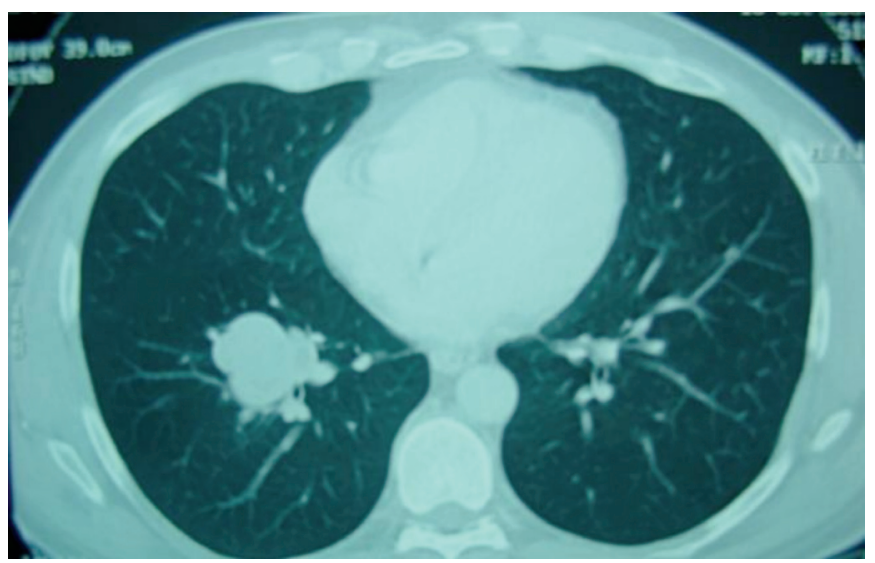

Figure 1. CT scan showing lobulated mass in the right lower lobe

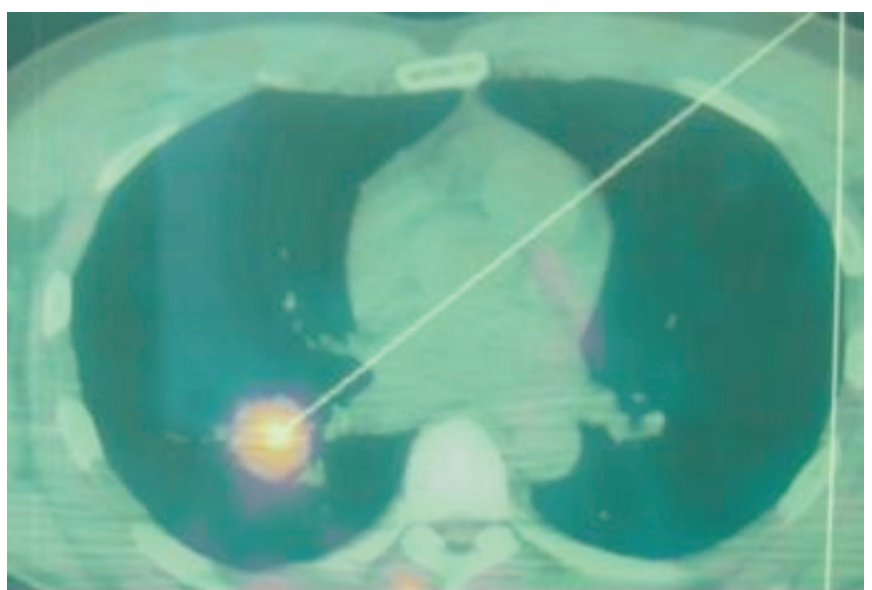

Figure 2. PET-CT with low SUV

The patient underwent a right thoracotomy, and a right lower lobectomy with radical mediastinal lymph node dissection for complete resection. The frozen section showed an undifferentiated tumor.

The postoperative course was uneventful and the patient was discharged on the 6th day after surgery in good clinical conditions.

The final pathology report showed a mass in the right lower lobe measuring $5 \times 3,5 \times 3,0 \mathrm{~cm}$, white to tan, with a well circumscribed border and a whirled pattern in contact with the bronchial wall (Figures 3A and $\mathrm{B}$ ). Histopathology revealed intersecting fascicles of spindle cells with elongated hyperchromatic nuclei and notable pleomorphism (Figure 4A). The cytoplasm was eosinophilic. The mitotic rate was 34 figures in 10
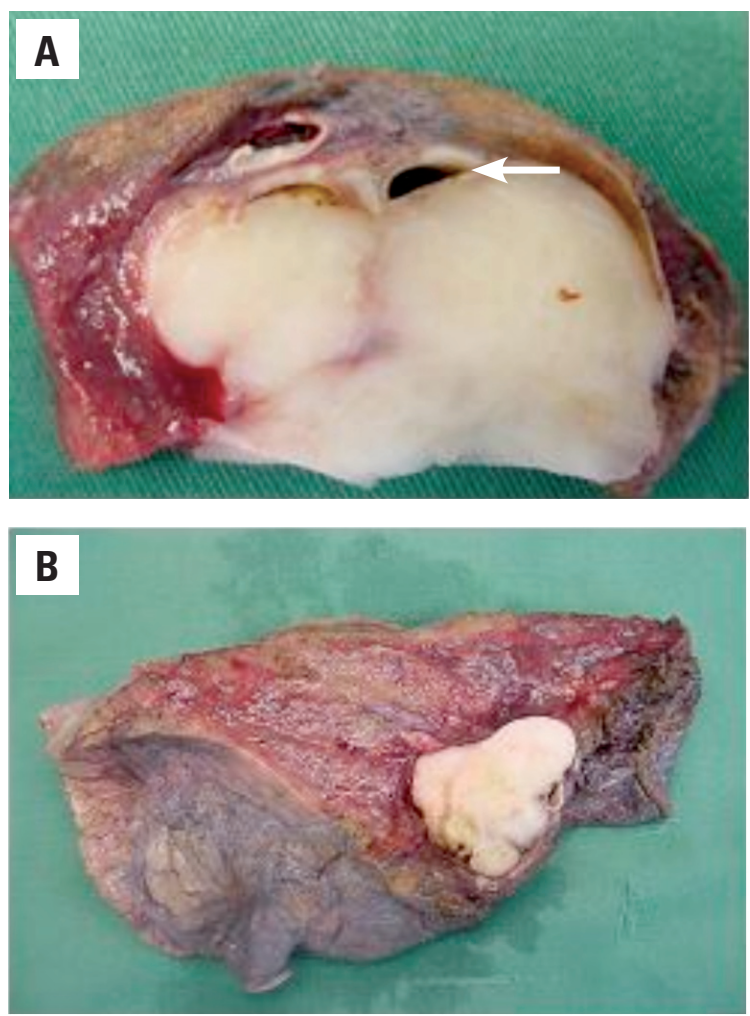

Figure 3. (A and B) Right lower lobe showing mass in contact with the bronchus (arrow)

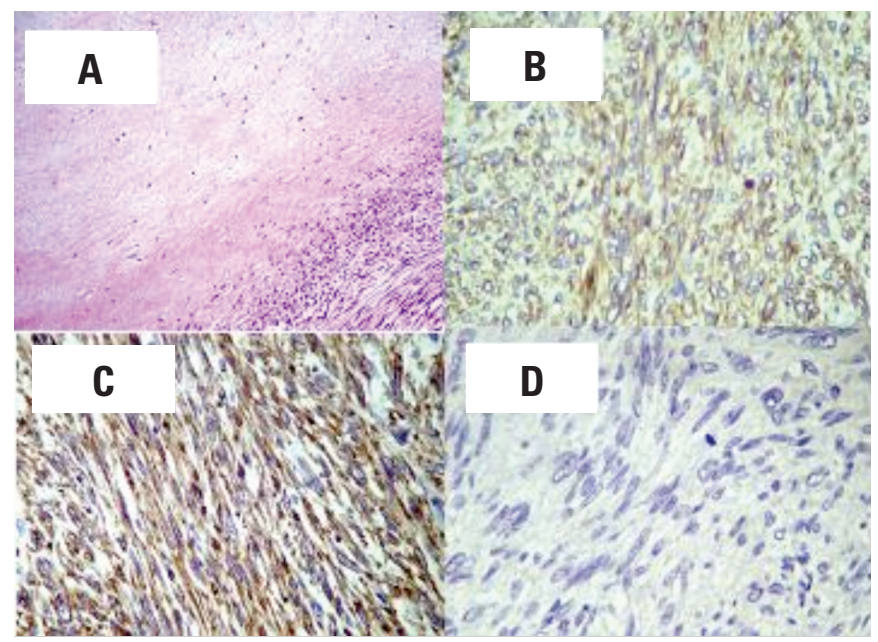

Figure 4. Immunohistochemistry. (A) Necrosis; (B) positive for desmin; (C) positive in smooth muscle; (D) negative for cytokeratin.

high-power fields, with some atypical mitoses. Necrosis was seen in $20 \%$ of the tumor (Figures $4 \mathrm{~B}$ and $4 \mathrm{C}$ ). The immunophenotype panel was positive for smooth muscle actin and desmin (Figure 4D). Stains for cytokeratins, S-100 protein, CD117/c-kit, CD34, and CD99 were negative. These findings were consistent with high-grade leiomyosarcoma originating from the bronchus. After a 3 -year follow-up there was no evidence of recurrence, and no further treatment was necessary. 


\section{DISCUSSION}

Primary pulmonary sarcomas are considered rare tumors, comprising only $0.5 \%$ of all lung malignancies ${ }^{(1-3)}$. Leiomyosarcoma is one of the most common histologic subtypes of sarcoma that occur in the lung, accounting for almost $30 \%$ of primary pulmonary sarcomas ${ }^{(2)}$. Pulmonary leiomyosarcomas have been observed inside bronchus $(20 \%)$, in lung parenchyma (70\%), or in pulmonary artery $(10 \%)^{(3)}$. Leiomyosarcomas usually occur during the 6th decade of life or later, predominantly in men. However, pulmonary artery leiomyosarcomas occur with an equal frequency in men and women, usually a decade or so younger, with a mean age at diagnosis of 50 years ${ }^{(5)}$.

Patients with pulmonary artery sarcomas present with chest pain, dyspnea or intractable congestive heart failure ${ }^{(6,7)}$. Primary pulmonary leiomyosarcomas are often asymptomatic, but patients can present with hemoptysis. Pulmonary artery lesions have a particularly poor prognosis, with few patients alive at 6 to 12 months $^{(2,6)}$.

At radiological analysis, these neoplasms manifest in the lung as well-margined smooth or lobular homogeneous nodules or large necrotic masses. The CT scan of the chest is crucial because the tumor can invade the contiguous thoracic structures (pleura, pericardium, vessels, and chest wall), and it allows the determination of local extension ${ }^{(6)}$. A CT scan was also helpful in distinguishing primary pulmonary tumor with chest wall invasion from a primary chest wall tumor with endothoracic extension ${ }^{(2)}$. All radiographic appearances resemble those of bronchogenic carcinoma. As reported elsewhere, the tumors were more often located in the upper lobes. In this context, the absence of cigarette smoking might alert the physician to the possibility of a sarcoma ${ }^{(1)}$.

Some studies conducted before 1985 were confusing because detailed immunohistochemistry (IHC) for diagnosing soft tissue sarcomas was not in current use. IHC presently allows a better classification of sarcomas, based on the predominant histological pattern of growth and/or cytological composition ${ }^{(8)}$.

However, a broad panel of antibodies is necessary to classify soft tissue sarcomas correctly. Positive immunohistochemical staining for vimentin, keratin, and EMMA does not allow distinguishing carcinoma from sarcoma. Positive staining for both vimentin and S100 protein allows distinguishing melanoma from sarcoma. Positive staining for desmin, alpha-actin, CD34, muscle actin (HHF35), and CD68 allows further subclassification of the sarcoma type. Immunohistologic studies in leiomyosarcoma show the regular presence of vimentin and desmin, with actin expressed in about $60 \%$ of $\operatorname{cases}^{(1,8)}$.

Complete resection has been shown in all prior series to be a significant predictor of improved survival(1,9).
For that reason, we believe that aggressive resection of centrally located primary pulmonary sarcomas is justified in otherwise healthy patients ${ }^{(10)}$. The objective of surgery is to achieve negative margins, and perform a thorough mediastinal lymph node dissection in an effort to adequately stage the patient $t^{(4)}$.

Surgical procedure, especially if not radical, may be completed by radiation therapy delivered at a dose of 50 to 60 Grays with classic fractioning. The more effective advances achieved in the management of soft tissue sarcomas were in the field of local control, obtained in 70 to $80 \%$ of patients. The role of conventional or intensive chemotherapy remains debatable ${ }^{(2,4)}$. Chemotherapy based on doxorubicin and/or ifosfamide regimen could be proposed for patients with advanced or metastatic sarcomas ${ }^{(2)}$, however, response rates are usually less than $20 \%$. High-dose chemotherapy is feasible and provides reasonable response rates in patients with soft tissue sarcomas, but cannot be considered as a common practice. Most series have reported a median survival close to 24 months, and a 3 -year survival between 17 and $50 \%{ }^{(1)}$.

In a report from the Mayo Clinic, size was thought to have an impact on survival ${ }^{(7)}$. In the most recent updated series of 42 patients from Memorial SloanKettering Cancer Center, there was a distinct trend in which survival was better in patients with tumors smaller than or equal to $5 \mathrm{~cm}^{(8)}$. According to Janssen et al., the grade of malignancy appeared to be a prognostic factor because of an associated higher frequency of local invasion and distant recurrence ${ }^{(4)}$.

\section{CONCLUSION}

Primary lung sarcomas represent a type of very rare and aggressive malignancy and all histologic subtypes can be found; in that, leiomyosarcoma is the most frequent tumor. Presenting symptoms are identical to those of bronchogenic carcinoma and treatment and prognosis do not differ from that of other soft tissue sarcomas.

Complete surgical resection is the treatment of choice whenever possible, with curative intent. Efforts should be made to define criteria for high-risk sarcomas, since in these cases patients might be considered for future adjuvant conventional or intensive chemotherapy protocols.

\section{REFERENCES}

1. Gladish GW, Sabloff BM, Munden RF, Truong MT, Erasmus JJ, Chasen MH. Primary thoracic sarcomas. Radiographics. 2002;22(3):621-37.

2. Mastroiani-Etieni B, Falchero L, Chalabreysse L, Chalabreysse L, Loire R, Ranchère $D$, et al. Primary sarcomas of the lung: a clinicopathologic study of 12 cases. Lung Cancer. 2002;38(3):283-9. 
3. Bacha EA, Wright CD, Grillo HC, Wain JC, Moncure A, Keel SB, et al. Surgical treatment of primary pulmonary sarcomas. Eur $\mathrm{J}$ Cardiothorac Surg. 1999;15(4):456-60.

4. Jansen JP, Mulder JJ, Wagenaar SS, Elbers HRJ, Van den Bosch JM. Primary sarcoma of the lung: a clinical study with long-term follow-up. Ann Thorac Surg. 1994;58(4):1151-5.

5. Capewell S, Webb JN, Crompton GK. Primary leiomyosarcoma of the lung presenting with a persistent pneumothorax. Thorax. 1986;41(8): 649-50.

6. Mayer F, Aebert H, Rudert M, Königsrainer A, Horger M, Kanz L, et al. Primary malignant sarcomas of the heart and greta vessels in adult patients- a single center experience. Oncologist. 2007;12(9):1134-42.
7. Nascimento AG, Unni KK, Bernartz PE. Sarcomas of the lung. Mayo Clin Proc. 1982;57(6):355-9.

8. Burt M, Zakowski M. Rare primary malignant neoplasms. In: Pearson FG, Deslauriers J, Ginsberg RJ, Hiebert CA, McKneally MF, Urschel Jr HC, editors. Thoracic surgery. New York: Churchill Livingstone; 1995. p. 807-26.

9. Magné N, Porsin B, Pivot X, Tchiknavorian X, Marcy PY, Foa C, et al. Primary lung sarcomas: long-term survivors obtained with iterative complete surgery. Lung Cancer. 2001;31(2-3):241-5.

10. Coindre JM, Terrier P, Bui NB, Bonichon F, Collin F, Le Doussal V, et al. Prognostic factors in adult patients with locally controlled soft tissue sarcoma: a study of 546 patients from the French Federation of Cancer Centers Sarcoma Group. J Clin Oncol. 1996;14(3):869-77. 